\title{
LUGARES DO SABER KAINGANG: CULTURA E ESPAÇO ESCOLAR ${ }^{1}$
}

\author{
Fernanda Machado Dill ${ }^{2}$ \\ Ayrton Portilho Bueno ${ }^{3}$
}

DOI: 10.5752/P.2316-1752.2019v26n39p183

\begin{abstract}
Resumo
Este artigo trata da análise dos diversos espaços voltados para a educação indígena Kaingang na Aldeia Kondá. Ao analisar a comunidade, percebe-se que a educação das futuras gerações transcende o espaço escolar formal e transita por outros lugares que possibilitam o protagonismo tanto das crianças quanto de anciãos e professores da comunidade. A partir da observação participante e dos registros de história oral, essas novas formas
\end{abstract}

\footnotetext{
1. Este artigo toma por base parte da investigação presente na tese de doutoramento de Fernanda Machado Dill, no Programa de Pós-graduação em Arquitetura e Urbanismo da Universidade Federal de Santa Catarina (UFSC), orientado pela professora Dra. Margarita Nilda Angeli Barretto.

2. Arquiteta e Urbanista pelas Faculdades Barddal de Artes Aplicadas, doutora em Arquitetura e Urbanismo pela Universidade Federal de Santa Catarina - UFSC. Pesquisa vinculada ao Programa de Pós-Graduação em Arquitetura e Urbanismo da Universidade Federal de Santa Catarina / PósARQ-UFSC. E-mail: fernanda.dill@gmail.com

3. Arquiteto e Urbanista pela Universidade Federal do Rio Grande do Sul - UFRGS, doutor em Arquitetura e Urbanismo pela Universidade de São Paulo - USP. Professor do departamento de Arquitetura e Urbanismo da Universidade Federal de Santa Catarina - UFSC. Pesquisa vinculada ao Programa de Pós-Graduação em Arquitetura e Urbanismo da Universidade Federal de Santa Catarina / PósARQ-UFSC E-mail: ayrtonbueno@hotmail.com
} 
de aprender e de ensinar são discutidas e relacionadas frente à cultura e à legislação vigente sobre a educação escolar indígena.

Palavras-chave: Arquitetura escolar. Educação indígena. Aldeia Kondá. Cultura Kaingang. 


\section{PLACES OF KAINGANG KNOWING: CULTURE AND SCHOOL SPACE}

\begin{abstract}
This article deals with the analysis of the diverse spaces dedicated to Kaingang indigenous education in Aldeia Kondá. When analyzing the community, it can be seen that the education of future generations transcends the formal school space and transits through other places that make it possible for the children, community elders and teachers to play a leading role. Based on participant observation and oral history records, these new ways of learning and teaching are discussed and related to the culture and current legislation on indigenous school education.
\end{abstract}

Keywords: School architecture. Indigenous Education. Kondá village. Kaingang culture.

\section{LUGARES DE CONOCIMIENTO DE KAINGANG: CULTURA Y ESPACIO ESCOLAR}

\section{Resumen}

Este artículo aborda el análisis de los diversos espacios dedicados a la educación indígena Kaingang en Aldeia Kondá. Mediante el análisis de la comunidad se da cuenta de que la educación de las generaciones futuras trasciende el entorno escolar formal y se mueve por otros lugares que permiten el papel de los niños y los ancianos de la comunidad y los maestros. Sobre la base de la observación participante y los registros de historia oral, estas nuevas formas de aprendizaje y enseñanza se discuten y se relacionan con la cultura y la legislación actual sobre educación escolar indígena.

Palabras-claves: Arquitectura escolar. Educación indígena. Pueblo de Kondá. Cultura Kaingang. 


\section{Introdução}

O povo Kaingang, em contexto similar ao de outros povos indígenas que habitam o território brasileiro, sofreu ao longo de décadas com contínuas ações do Estado que objetivavam sua assimilação pela sociedade nacional e o abandono da cultura tradicional. No entanto, no interior das próprias comunidades, iniciou-se um processo de luta e resistência para garantir a continuidade cultural e o direito de manter seu modo de viver específico.

Nesse contexto, a educação indígena emerge como principal instrumento voltado à afirmação de práticas culturais tradicionais, sobretudo no que diz respeito ao aprendizado da língua materna, das relações com a natureza e da fabricação do artesanato. No entanto, os espaços escolares disponíveis nem sempre são adequados para as atividades de ensino pretendidas. Nas comunidades Kaingang do estado de Santa Catarina, observam-se diversas configurações espaciais das escolas, alguns espaços sem aderência à cultura ${ }^{4}$ dificultam o aprendizado de práticas tradicionais e não geram sentimento de pertencimento e identificação entre escola e comunidade, limitando as potencialidades da relação ensino-aprendizagem no meio indígena. Outros resultados são observados em espaços escolares cujos processos projetuais contemplaram eta-

4. Pode-se citar o exemplo das Escolas das Terras indígenas Toldo Pinhal, Toldo Imbú e Toldo Chimbangue. 
pas participativas, resultando em lugares intimamente ligados às necessidades práticas e valores simbólicos das comunidades indígenas ${ }^{5}$.

Como possibilidade de articular esses contextos extremos, identifica-se a comunidade da Aldeia Kondá, que teve seus espaços educacionais transformados e adaptados ao longo do tempo, equilibrando lugares específicos para a educação escolar e outros que transcendem as fronteiras da escola e têm a produção do saber voltada à continuidade cultural.

Este artigo se propõe a descrever e discutir os espaços formais e informais utilizados na educação da Aldeia Kondá, considerando que, ao abordar o Povo Kaingang em suas especificidades culturais, as atividades curriculares desenvolvidas no espaço escolar suprem parcialmente as inúmeras facetas que compõem a educação indígena, construída coletivamente com o objetivo principal da valorização do saber tradicional e afirmação das especificidades culturais.

Para construir essas reflexões, foram adotadas estratégias metodológicas que compreendem a pesquisa bibliográfica/teórica a respeito da cultura Kaingang e da regulamentação voltada à educação escolar indígena, visitas

5. Escola indígena Cacique Vankre da Terra indígena Xapecó. 
exploratórias, relatos de história oral e observação participante.

\section{Metodologia}

Para a definição das estratégias metodológicas adotadas na pesquisa, buscou-se uma abordagem multidisciplinar, pois história, antropologia, geografia e arquitetura e urbanismo têm encontrado caminhos diferentes para responder aos problemas de pesquisa nos estudos de grupos culturalmente específicos.

As visitas exploratórias representaram a primeira aproximação com a comunidade de estudo e foram registradas por meio de desenhos, anotações e fotografias (REINGHANTZ et al, 2008). Base da pesquisa exploratória, as visitas têm como característica, segundo Theodorson e Theodorson (1970), o caráter preliminar na intenção de tornar o pesquisador familiar com o grupo de estudo. Foram realizadas visitas de caráter exploratório, com foco na identificação dos lugares voltados para a educação e atividades de ensino na comunidade.

Os relatos de história oral consistem em uma prática de apreensão de narrativas destinadas a recolher testemunhos e promover análises de processos sociais do presente. A História Oral contribui na construção de uma visão mais concreta da dinâmica de funcionamento da trajetória do grupo social que se pretende estudar, além 
de ser um procedimento destinado à constituição de novas fontes para a pesquisa histórica (LOZANO, 2002). A perspectiva de dar igual valor à fonte escrita e à fonte oral e o anseio de ouvir o que os indígenas falam de si mesmos, de sua comunidade, da forma de educar as crianças e do lugar onde vivem, constituem o cerne do interesse pelo uso da história oral, especialmente no que tange o objeto de estudo, haja vista a representatividade da tradição oral entre os Kaingang, tornando a história oral fundamental para a compreensão do seu modo de viver.

Por fim, a observação participante é utilizada por acreditar que a apreensão de um contexto social específico só pode ser concretizada se o observador puder imergir e se mesclar ao grupo social investigado, de modo a reduzir as resistências e o distanciamento entre pesquisador e o grupo. Segundo Mann, é uma "[...] tentativa de colocar o observador e o observado do mesmo lado, tornando o observador um membro do grupo de modo a vivenciar o que eles vivenciam e trabalhar dentro do sistema de referência deles" (MANN, 1970, p. 96). Só então, pode-se compreender a relação estabelecida no cotidiano, entre os espaços, nas atividades de ensino e os significados atribuídos pelo grupo. A utilização do olhar da etnografia possibilita a obtenção de informações que não estão inicialmente no escopo das técnicas de investigação, mas que representam o olhar do pesquisador, do outro, de quem está apenas temporariamente dentro da comuni- 
dade.

Essa investigação é construída no diálogo entre etnografia e história oral, admitindo etapas exploratórias, de aproximação e imersão junto à comunidade com o olhar voltado para os espaços produzidos para abrigar práticas culturais, educacionais e demais relações humanas.

\section{Educação escolar indígena}

A presença de escolas em comunidades indígenas inicia-se por meio de atividades missionárias, que atendiam a uma política de desagregação e dominação. Antes desse processo impositivo, a educação indígena consistia nos ensinamentos passados de geração para geração cotidianamente, com o objetivo de garantir a sobrevivência e continuidade cultural do grupo. As atividades, majoritariamente lideradas por anciãos e anciãs, ocorriam na sombra de árvores, em torno do fogo de chão e nos longos percursos realizados para a coleta e caça. O mundo habitado tornava-se uma vasta sala de aula, assim, mais do que espaços de permanência, os lugares de passagem eram fundamentais para os processos de aprendizagem intergeracional.

A partir do contato com os não indígenas, as formas tradicionais de educação foram invisibilizadas e destituídas no processo de inserção do ensino escolarizado (ROSA, 2009), que tinha como objetivo a formação de mão de 
obra voltada principalmente ao manejo da terra, tornando os aldeamentos mais produtivos e economicamente lucrativos. Com a criação do Serviço de Proteção aos Índios e Localização de Trabalhadores Nacionais (SPILTN), em 1910, as ações se voltaram à 'proteção' dos indígenas durante sua integração à sociedade nacional (TASSINARI, 2008).

Esse modelo deu continuidade ao processo civilizatório e, por consequência, tornou as populações indígenas dependentes das ações governamentais. Na década de 1960, o novo modelo proposto pela Fundação Nacional do Índio (FUNAI) indicou um avanço no pensamento sobre educação e infância indígenas. Mesmo com a continuidade de políticas de assimilação cultural, nas escolas identifica-se o ensino bilíngue e a presença de monitores indígenas, aspectos que respondem aos esforços e lutas por direitos relacionados à educação diferenciada e valorização cultural.

A partir de 1970 surgiram as primeiras orientações para a educação escolar indígena, resultado dos movimentos de luta pela demarcação das terras tradicionais, pelo reconhecimento das diferenças étnicas e pela continuidade cultural. Essa temática passou a ser discutida nas comunidades e viabilizou a criação de leis específicas para a educação escolar indígena. O movimento, que se fortaleceu em plena ditadura militar, foi formado por represen- 
tantes dos povos indígenas e participou da Assembleia Constituinte, contribuindo no processo de aprovação da Constituição de 1988.

Os direitos conquistados com a Constituição de 1988 (CF/88), como o Decreto n²6, de 4 de fevereiro de 1991 (BRASIL, 1991) e a Lei de Diretrizes e Bases da Educação Nacional - LDB/96 (BRASIL, 1996), dão início a uma nova etapa na educação indígena no Brasil, que valoriza a diversidade étnica ao reconhecer especificidades culturais identitárias.

O protagonismo das comunidades indígenas aliado a setores historicamente comprometidos com a causa fez com que, a partir desse momento, alguns direitos fossem estabelecidos por lei: o respeito às especificidades culturais, à organização social, seus costumes, línguas, crenças, tradições e principalmente o direito à educação específica e diferenciada, reconhecendo e uso de línguas maternas e processos próprios de aprendizagem.

O Referencial Curricular Nacional para a Educação Escolar Indígena (RCNEI, 1998) estabelece que a educação escolar indígena deve ser comunitária, intercultural, bilíngue, específica e diferenciada. Comunitária, porque deve ser conduzida pela comunidade indígena, de acordo com seus projetos, suas concepções e seus princípios. Isso se refere tanto ao currículo quanto aos modos de admi- 
nistrá-la. Inclui liberdade de decisão quanto ao calendário escolar, à pedagogia, aos objetivos, aos conteúdos, aos espaços e momentos utilizados para a educação escolarizada. Intercultural, porque deve reconhecer e manter a diversidade cultural e linguística; promover comunicação entre experiências socioculturais e históricas diferentes, considerando equidade entre culturas, estimulando o entendimento e o respeito entre seres humanos de identidades étnicas diferentes, contribuindo no combate as relações de desigualdade construídas historicamente.

Deve ser bilíngue, pois entende-se que as tradições culturais, os conhecimentos acumulados, a educação das gerações mais novas, as crenças, o pensamento e a prática religiosos, as representações simbólicas, a organização política, os projetos de futuro, ou seja, todos os aspectos que envolvem a continuidade sociocultural das sociedades indígenas são, na maioria dos casos, manifestados através da oralidade e do uso de mais de uma língua. Mesmo os povos indígenas que são hoje monolíngues em língua portuguesa continuam a usar a língua de seus ancestrais como um símbolo poderoso para onde confluem muitos de seus traços identitários, constituindo, assim, um quadro de bilinguismo simbólico importante. Por fim, deve ser específica e diferenciada, pois precisa ser concebida e planejada como reflexo das aspirações particulares do povo indígena ao qual a comunidade pertence, viabilizando autonomia da escola indígena em rela- 
ção a determinados aspectos que regem o funcionamento e orientação da escola não indígena.

Entende-se que entre os povos indígenas, a educação se assenta em princípios que lhes são próprios. Consideram, em sua visão de sociedade, relações que transcendem as humanas, admitindo seres e forças da natureza com as quais estabelecem igualmente relações de cooperação e intercâmbio para adquirir e assegurar a estabilidade e equilíbrio da comunidade. Tais sociedades, originalmente de tradição oral, são menos marcadas por desigualdade internas e mais articuladas pela obrigação da reciprocidade entre os grupos que as integram, o que não impede a constatação de diversas assimetrias e disputas internas como será abordado a seguir.

A formação de crianças e jovens é um processo articulado, responsabilidade da comunidade como um todo e contempla diversos processos de aprendizado, dos quais apenas uma parcela se constrói na escola, por isso a importância da diversidade de espaços de construção do conhecimento em contextos comunitários locais. Os princípios da educação escolar indígena incluem ainda a recuperação de suas memórias históricas, a reafirmação de suas identidades étnicas, a valorização de suas línguas e ciências, o acesso às informações, conhecimentos técnicos, científicos e culturais da sociedade nacional e demais sociedades indígenas e não indígenas (RCNEI, 
1998).

Com o intuito contribuir para viabilizar a educação escolar indígena, a FUNAl elaborou um documento de orientação para a construção de escolas em aldeias indígenas, pois se entende que os lugares responsáveis por abrigar essas atividades educacionais precisam estar de acordo com a lógica cultural da comunidade que pretendem atender. $\mathrm{O}$ documento orienta que, após um povo demonstrar interesse pela implantação de uma escola em seu território, os procedimentos se iniciarão com uma reunião entre a comunidade, a FUNAI local e a instituição que será responsável pela construção e operacionalização da escola (FUNAl, 2018).

Dessa forma, deve ser realizada uma consulta livre, prévia e informada à comunidade, conforme estabelecido na Convenção n¹69/OIT, com discussões sobre o projeto a ser realizado: se há a adequação dos moldes arquitetônicos à cultura local (tendo em vista que a legislação correspondente permite a realização de projetos que atendam as especificidades culturais e as condições ambientais da comunidade), a definição do local da obra na comunidade, quais e quantas turmas serão atendidas, etc. Novamente, considera-se a importância de o plano da edificação buscar, de alguma forma, atender ao projeto pedagógico da educação diferenciada. 


\section{A cultura Kaingang}

Essa pesquisa entende a cultura como um sistema complexo aprendido, no qual qualquer disposição genética ou geográfica é superada pelas práticas vivenciadas e observadas cotidianamente. Assim, torna-se um potencial instrumento de identificação coletiva e por isso deve ser ensinada e aprendida no interior das comunidades, fazendo dos espaços educacionais, possíveis potencializadores da cultura. As especificidades culturais que caracterizam o Povo Kaingang constituem um amplo universo. Por isso, nesse artigo serão priorizados os aspectos da cultura tradicional que possuem relação com os lugares destinados à educação na contemporaneidade.

Os Kaingang, assim como outros grupos Jê, são estruturados a partir de uma organização social dualista, patrilinear, exogâmica e matrilocal (TOMMASINO; FERNANDES, 2001). Ou seja, compostos por dois grupos de linhagens de parentesco transmitidas pelo pai aos descendentes, nos quais as alianças matrimoniais sempre se dão entre indivíduos pertencentes às metades opostas e, após o casamento, o noivo vai morar com os pais da noiva.

As metades criadoras da sociedade recebem os nomes dos heróis mitológicos Kamé e Kairu. No mito de origem coletado por Telêmaco Borba (1908), encontra-se uma versão da cosmologia dualista Kaingang: nesse mito Kamé e 
Kairu produzem não apenas as divisões entre humanos, mas também a divisão entre os demais seres e elementos da natureza conforme ilustra a Figura 1:

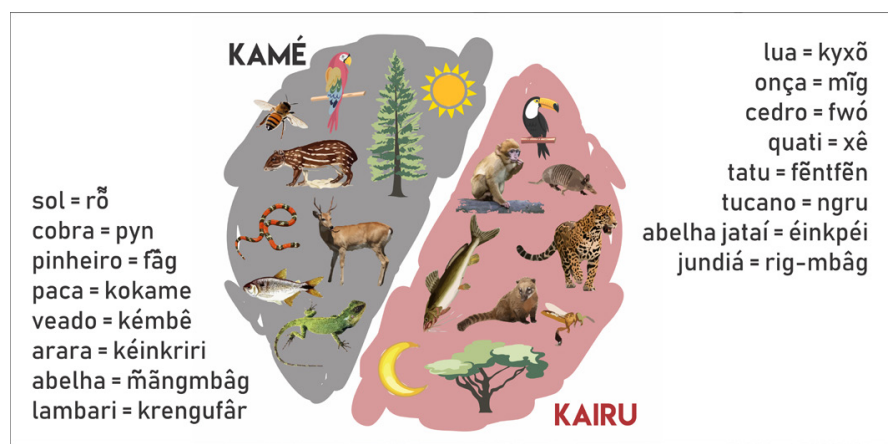

Figura 1 | Divisão dos seres da natureza Kamé e Kairu Fonte: DILL, 2019

Segundo a tradição Kaingang, o Sol é Kamé e a Lua é Kairu, o pinheiro é Kamé e o cedro é Kairu, o lagarto é Kamé e o macaco é Kairu, e assim por diante (BORBA, 1908). Essa divisão está embasada na noção de complementaridade entre as metades, valorizando a beleza existente na articulação entre as diferenças e os opostos.

Seguindo a mesma lógica da complementariedade e do equilíbrio alicerçado na diferença, se estabelecem as relações entre gêneros e gerações nas comunidades. Apesar de os homens assumirem grande parte das posições de liderança perante o mundo não indígena, na observação 
das relações internas percebe-se que as mulheres participam diretamente das tomadas de decisão e têm assumido, principalmente nos últimos anos, protagonismo nas atividades voltadas à educação e na interface com a sociedade não indígena do entorno.

Ao abordar a questão geracional, percebe-se que as pessoas com mais idade, independente do gênero, detém status de respeito, representatividade e liderança interna da aldeia. Elas são as principais responsáveis pela forma como os diferentes tipos de capital ${ }^{6}$ são percebidos e reconhecidos como legítimos pelo grupo ${ }^{7}$.

Cabe destacar que a sociedade Kaingang é marcada por contínuos processos de conflito interno, evidenciando a assimetria das relações sociais. No entanto, quando indagados sobre essas questões, os indígenas colocam que o conflito, as disputas e a não concordância faz parte da cultura, uma vez que, por meio dessas situações, lados opostos têm voz e representatividade, viabilizando, portanto, que todos os membros da comunidade participem das decisões.

Em termos de organização parental, o grupo familiar representa a unidade social mínima Kaingang, formado por

6. Entende-se aqui capital como poderes sociais fundamentais (BOURDIEU, 1987).

7. Toma-se aqui o conceito de capital simbólico de Bourdieu (1987, p.4) e representa o prestígio atribuído aos outros capitais tomando-os legítimos perante o grupo. 
uma família nuclear (pais e filhos) de acordo com a lógica da matrilocalidade. Esses grupos familiares fazem parte de unidades sociais maiores, chamados grupos domésticos, formados, idealmente, por um casal de anciãos, seus filhos e filhas solteiras, suas filhas casadas, seus genros e netos. Tal grupo doméstico não ocupa, necessariamente, uma mesma habitação, porém, um mesmo território (TOMMASINO e FERNANDES, 2001).

Os grupos familiares ainda hoje orientam grande parte da configuração espacial da aldeia (Figura 2) e são formados por conjuntos de três a dez residências em torno da moradia de uma anciã.

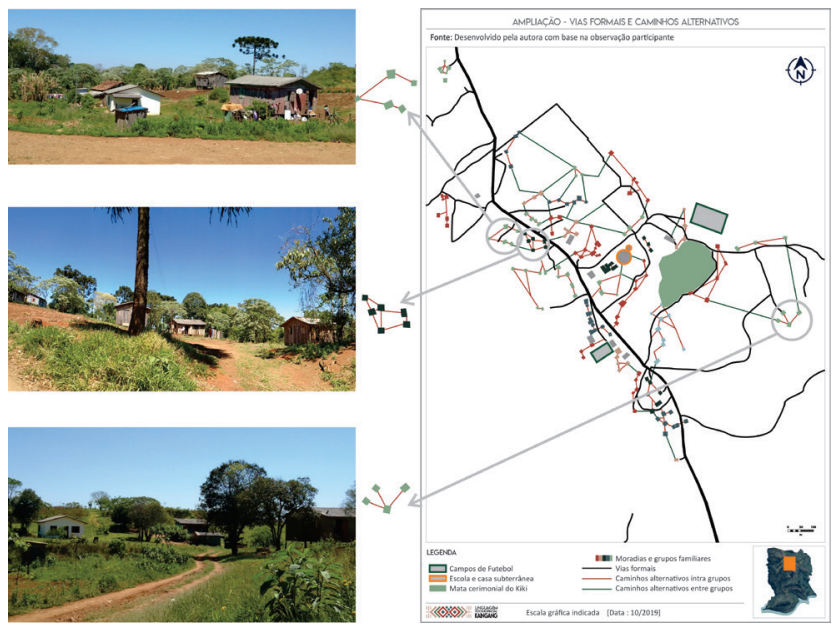

Figura 02 | Caminhos alternativos Aldeia Kondá Fonte: DILL, 2019 
Atualmente as casas se posicionam de forma a conectarem o núcleo familiar e não priorizando a orientação da fachada principal para a via de veículos, como se observa na cidade não indígena. Para consolidar essa conexão, as pessoas criam caminhos alternativos ao longo de toda a aldeia estabelecendo as ligações intragrupo (linhas vermelhas) e entre grupos familiares (linhas verdes) como mostra a Figura 2.

Complementarmente ao posicionamento das moradias, as informações a respeito dos assentamentos humanos constituídos pelos grupos Kaingang antes do contato com os não indígenas são resultado de pesquisas arqueológicas que vêm se desenvolvendo desde o século XIX. As organizações majoritariamente localizadas próximas dos cursos de água doce vão desde habitações a céu aberto, passando por abrigos subterrâneos e semissubterrâneos até a construção de abrigos artificiais sobre o solo, no entanto, seguem a lógica de organização espacial acima descrita até a atualidade. Nesse artigo, é priorizada a apresentação dos abrigos semissubterrâneos como prática tradicional em função da identificação dessas estruturas na comunidade da Aldeia Kondá e sua representatividade enquanto espaço educacional.

Segundo a descrição das estruturas elaborada por D'Angelis e Veiga (2003) sobre a cova circular que delimitava a estrutura subterrânea, erguia-se uma cobertura de folhas 
sustentada em uma armação de madeira, em parte fixada na base da casa, assim como em parte fixada nas bordas laterais da cova, inclusive com o auxílio de pedras (Figuras 3 e 4).
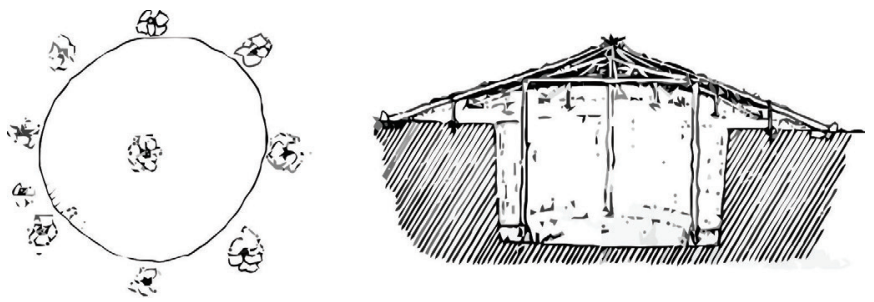

Figura 3 | Suportes de vigamento do telhado e Casa subterrânea grande Fonte: Adaptado de D’ANGELIS; VEIGA, 2003. P. 07 e 08
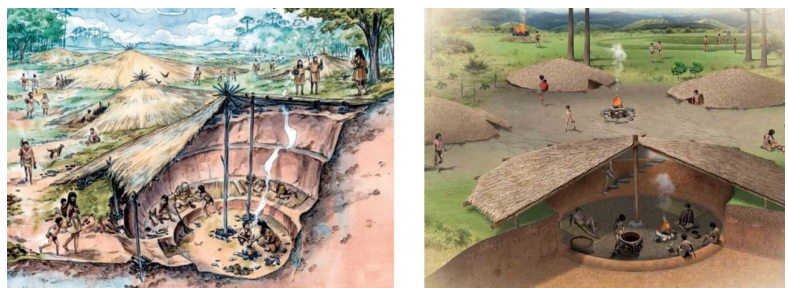

Figura 4 | Casas subterrâneas Kaingang Fonte: (MULTIPLICA, 2016)

A predominância dos Kaingang em terrenos acidentados e em regiões de clima frio e com ventos intensos justificava a adoção dessas estruturas subterrâneas, na medida em que se aproveitavam das preexistências to- 
pográficas para a construção das casas (Figura 4A) e do conforto térmico proporcionado pelas paredes de terra. Quanto à quantidade de casas nos agrupamentos, as pesquisas destacam que, na maioria dos casos, os conjuntos eram compostos por grupos de até vinte estruturas e apenas em um número pouco significativo de sítios arqueológicos encontrou-se casas subterrâneas isoladas (REIS,2007). Reforça-se, assim, a teoria anteriormente apresentada dos grupos familiares como estrutura social fundamental Kaingang ainda antes do contato e que se mantém na atualidade.

Levy-Strauss (2015) aponta que a configuração espacial das aldeias nem sempre reflete a noção de estrutura de organização social como um espelho, de maneira que uma reflita a outra por completo, mas quando há correlação entre elas, como ocorre no caso dos Kaingang, torna-se possível tal ligação. Percebe-se que os agrupamentos de casas constituem pequenas centralidades em torno das moradias das anciãs na comunidade, formando um círculo de proteção e valorização da sabedoria dessas pessoas. Nesse sentido, o capital que orienta as relações de poder na comunidade está mais relacionado com o saber tradicional (capital simbólico e cultural) do que com o capital financeiro, com as diferenças entre gêneros e outras relações de assimetria que possam existir.

Outro aspecto cultural relevante, também ligado ao saber 
anciãos e derivado da dualidade Kamé e Kairu, é o Ritual do Kiki, uma festa para os mortos recentes, organizada pelos consanguíneos do morto em sua homenagem, que integra durante o ritual as metades tribais. Esse culto é apontado como a base e a expressão mais forte da cultura espiritual dos Kaingang e a manutenção desse ritual é fundamental para a manutenção da cultura desse povo (SILVA, 2011).

Esse princípio de complementaridade observado nos rituais, na estrutura social e nas ocupações territoriais Kaingang é comunicado também por meio de sistema de representações visuais presente no grafismo e replicado em outras manifestações materiais como no artesanato, importante símbolo de afirmação cultural. Pelo menos duas categorias podem ser analisadas para a identificação das metades clânicas na cestaria: a forma do artefato e o grafismo nela impresso. A partir dessas referências, a Figura 5 ilustra um estudo realizado em alguns exemplares de artesanatos Kaingang: 


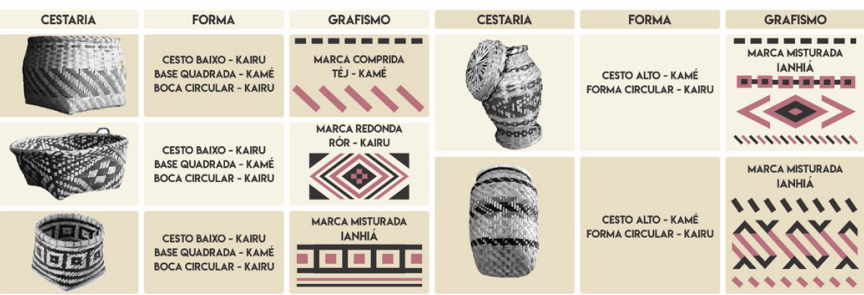

Figura 5 | Cestaria Kaingang - grafismo e forma

Fonte: DILL, 2019

O sistema de representações visuais expresso pela cultura material Kaingang marca o pertencimento de seus integrantes às metades tribais e acentua a necessidade da articulação entre essas partes complementares para o funcionamento adequado dessa sociedade indígena. Cabe ainda o destaque que o grafismo impresso no artesanato sobrepõe à forma no que diz respeito à identificação das metades, pois inúmeras vezes a função prática do artefato define seu formato, sendo então utilizado tanto por Kamés quanto por Kairus. Por outro lado, o grafismo, independente da forma do objeto, pode identificar a marca a qual pertence o indivíduo.

Os estudos em torno das características sociais e os relatos sobre a ocupação espacial indígena, bem como a identificação do grafismo e da língua como fatores de diferenciação cultural, apresentam as especificidades 
do Povo Kaingang e fundamentam a análise em torno da educação indígena na Aldeia Kondá.

\section{Aldeia Kondá e os lugares do saber}

A população que constitui a Reserva Indígena Aldeia Kondá pertence ao Povo Kaingang e habita a área desde 1999, quando ela foi destinada à sua ocupação, uma vez que seu território tradicional não poderia ser devolvido, pois constitui atualmente o centro do município de Chapecó-SC.

$\mathrm{Na}$ comunidade foram identificados seis lugares focados no ensino das crianças, conforme ilustra a Figura 6. A Escola e estruturas complementares, a Casa Subterrânea, a Mata Cerimonial e a casa de um dos anciãos, que se localizam próximos entre si, constituindo uma centralidade na Aldeia com foco na educação. Ainda, localizado distante desse ponto, está o Rio Uruguai, outro espaço do saber Kaingang. 


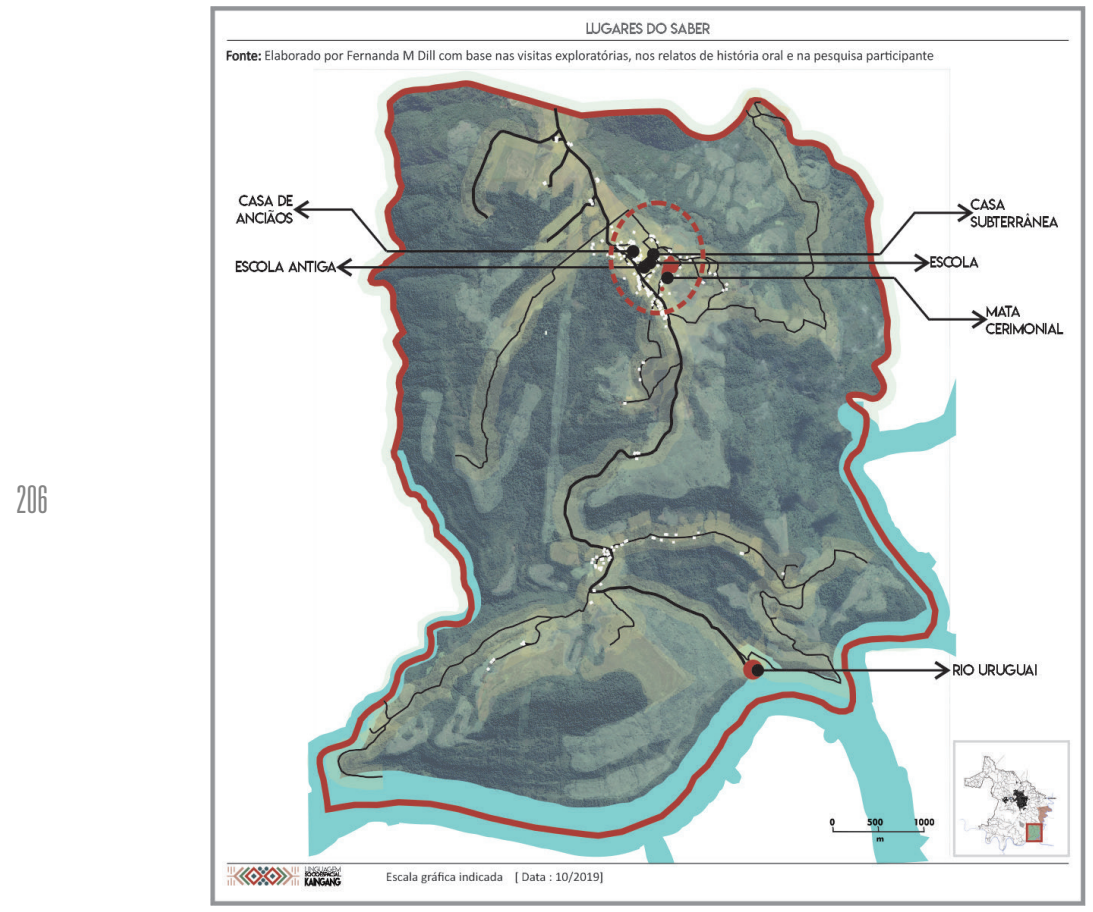

Figura 6 | Lugares do saber - Aldeia Kondá Fonte: Elaboração própria 
A Escola Indígena Sape ty kó, inaugurada em 2016, foi construída em alvenaria, no formato de um dodecaedro (Figura 7) e segue o padrão da escola EIEB Cacique Vanhkre que, inaugurada na Terra Indígena Chapecó no ano 2000, configura o padrão adotado pelo governo do estado de Santa Catarina e foi concebida com a participação da sua comunidade. Tal processo de participação não se repetiu no projeto da escola na Aldeia Kondá, fato esse que gerou revolta nos estudantes e professores e retardou a apropriação dos usuários nesse espaço. Por essa razão, mesmo com pouco tempo de uso, a comunidade discute e sugere uma reforma para a ampliação na estrutura central, que além de aumentar a área da escola, trará a identidade da aldeia para a edificação, remetendo o Sape ty kó (Chapéu de cipó) que dá nome à escola.
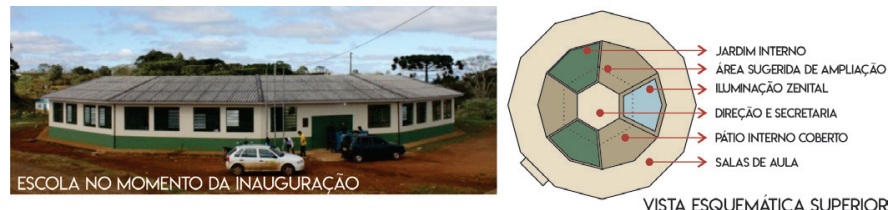

CROQUI DA AMPLIAÇÃO

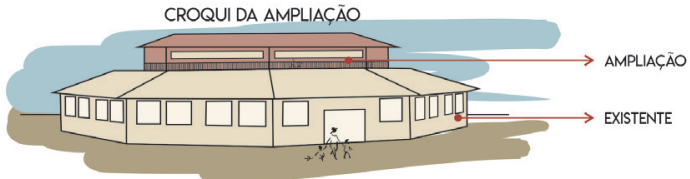

Figura 7 | Escola Sape ty kó - inauguração e ampliação sugerida Fonte: DILL 2019 
Passados três anos da sua inauguração, a comunidade promoveu uma série de adaptações e personalizações, construindo o sentimento de pertencimento em relação ao espaço escolar. O conjunto de fotografias da Figura 8 releva os traços de identificação observados:
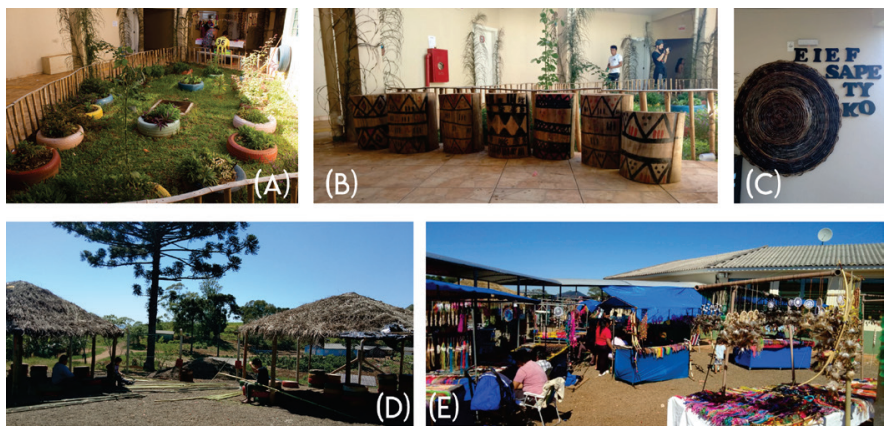

Figura 8 | Interior da Escola Sape Ty Kó Fonte: DILL 2019

A pequena horta de ervas medicinais cercada com bambu (Figura 8 A) foi construída no pátio interno com a cooperação entre professores, alunos e anciãos da comunidade. Além de trazer a vegetação para o interior da escola, aproximando as crianças da natureza, por meio dessa prática são ensinadas técnicas de cultivo e conhecimentos relacionados ao uso das ervas medicinais. Também, os bancos construídos com troncos de árvores foram pintados com o grafismo correspondente às metades tribais Kamé e Kairu (Figura 8 B) e, nesse processo, as crian- 
ças se identificam como pertencentes a uma ou outra metade, aprendem sobre a complementariedade que rege a vida Kaingang e reafirmam suas marcas frente à comunidade escolar. O Sape ty $k^{\circ}{ }^{8}$ exposto na parede da escola (Figura $8 \mathrm{C}$ ) representa o artesanato produzido na comunidade e valoriza as especificidades desta frente às demais sociedades Kaingang da região.

No pátio externo à escola, foram construídas, por professores e anciãos, estruturas circulares, feitas com madeira e cobertas com folhas de palmeira trançadas (Figura 8 D). Esses lugares servem como salas de aula ao ar livre e também como suporte para as atividades realizadas durante a semana cultural (Figura $8 \mathrm{E}$ ), dentre as quais se destacam o preparo das comidas tradicionais no fogo de chão e a comercialização do artesanato, ações ligadas ao caráter intercultural da educação, uma vez que elabora a interação entre indígenas e não indígenas que vêm participar do evento.

O conhecimento tradicional e a valorização da memória espacial dos anciãos pela comunidade motivaram a construção de uma estrutura semissubterrânea ao lado da escola. O espaço (Figura 9) também tem sido utilizado como sala de aula, além de ser visitado por crianças e

8. O simbolismo em torno do artefato está ligado à história do nome do município de Chapecó, contada pelos anciãos e passada de geração para geração. Nela fica evidente a relação entre os Kaingang e o território onde localiza-se cidade, sua terra tradicional, justificando o valor simbólico dessa representação. 
adultos não indígenas que desejam conhecer a comunidade, estimulando a presença dos anciãos nas atividades escolares e culturais.
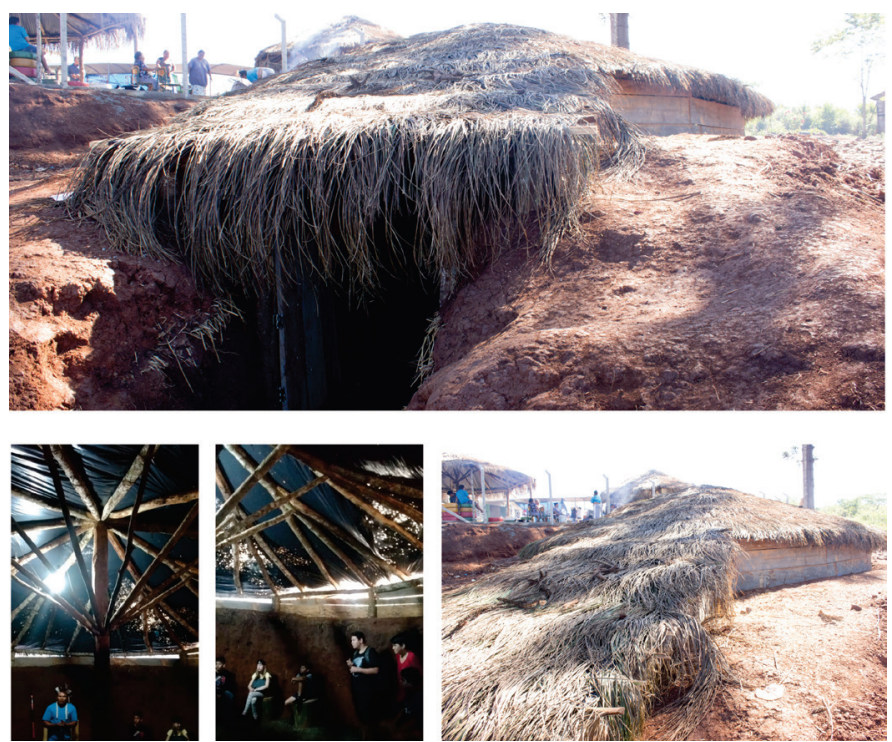

Figura 9 | Casa subterrânea

Fonte: Acervo pessoal

A partir do momento que é construído um espaço de acolhimento para contar e ouvir histórias, valorizando o saber fazer tradicional, esse lugar torna-se um convite para que ocorram tanto práticas intergeracionais tradicionais quanto interculturais. A casa envolve dimensões que vão além de sua materialidade, congregando significados 
de valorização de técnicas construtivas tradicionais, dos lugares de encontro e da sabedoria dos idosos na cultura Kaingang.

Ao pensar a valorização dos ensinamentos dos anciãos e o resgate da memória coletiva, identifica-se outro lugar de educação indígena, a Mata Cerimonial do Kiki (Figura 10). Trata-se de um espaço de vegetação nativa, onde foi realizado o último Ritual do Kiki, em 2014, e que permanece sendo um espaço simbólico valorizado pela comunidade, uma vez que constitui uma sala de aula em meio a natureza, onde se realizam atividades culturais como brincadeiras, fabricação de armadilhas de caça, batizados e exposições
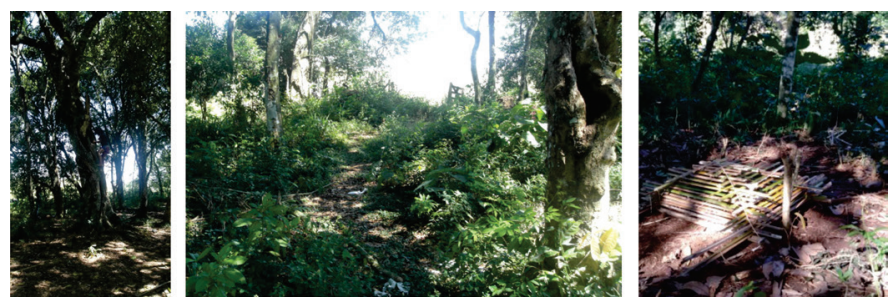

Figura 10 | Mata cerimonial do Kiki Fonte: Acervo próprio

Além de valorizar a importância da recuperação e preservação ambiental, fundamental para a educação infantil, a vivência desse espaço aproxima as crianças dos espíritos da mata, símbolos referenciais da Cosmologia Kaingang. 
Outro lugar de construção do conhecimento indígena identificado é a casa de uma das anciãs (Figura 11), também localizada nas proximidades da escola. $\mathrm{O}$ artesanato representa a principal fonte de renda da comunidade $e$ abrange, além da questão financeira, um aspecto de diferenciação cultural. "Nas cestas estão nossas metades e nosso jeito de viver" afirmou um dos anciãos que acompanhava um dos passeios pela aldeia.
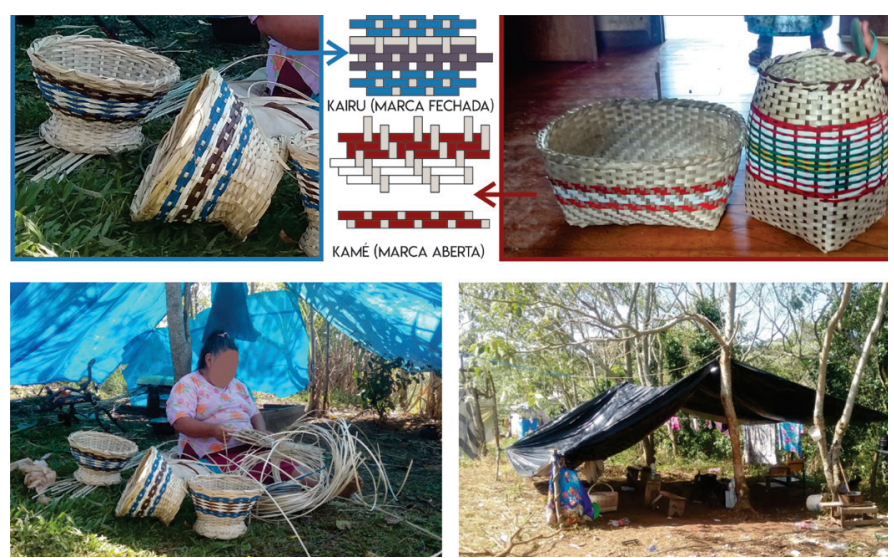

Figura 11 | Artesanato da Aldeia Kondá Fonte: Elaboração própria

O processo produtivo do artesanato, que compreende desde a coleta do material, seu preparo, até o resultado final com o grafismo formado pelo trançado, representa o olhar do povo Kaingang para sua própria cultura e para o mundo que habita. Mais importante que o produto mate- 
rial do artesanato, as experiências passadas de geração para geração durante o processo de ensino-aprendizagem do saber fazer tradicional representam outro aspecto fundamental para a compreensão dessa cultura.

Os anciãos, enquanto ensinam as técnicas de cestaria e de produção de outros artefatos, na maior parte das vezes em torno do fogo de chão, compartilham também as memórias dos antepassados, ensinam a língua Kaingang para as crianças e contam histórias e lendas tradicionais. Essas pessoas, com mais idade, ocupam lugar de liderança e respeito nas comunidades, pois os Kaingang acreditam que as experiências por eles vividas, trazem sabedoria para as novas gerações que podem continuar as lutas dos mais velhos e aprender com os ensinamentos que eles têm para compartilhar.

Por fim, os cursos d'água que definem os limites da aldeia constituem outro espaço do saber, a exemplo a exemplo do Rio Uruguai (Figura 12).
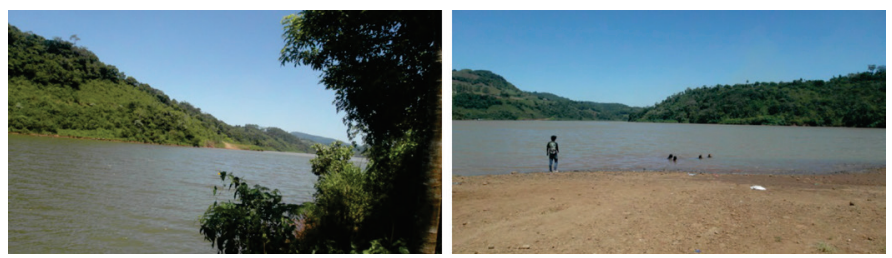

Figura 12 | Rio Uruguai - vista de dentro da Aldeia Fonte: Acervo próprio 
A partir dos percursos trilhados até chegar aos cursos d' água $^{9}$ e da vivência nos rios, os mais velhos e professores indígenas explicam para as crianças sobre a diversidade da vegetação, mostram os remédios do mato, conversam sobre os animais e a sua importância para o equilíbrio da vida na comunidade, e ensinam estratégias de pesca ${ }^{10}$ tradicional, construção de caiaques para travessia dos rios e a influência do movimento das águas para o plantio e a colheita. O movimento da água e os deslocamentos necessários para acessar esses lugares fazem com que o processo de aprendizagem baseado na troca de experiências entre gerações em espaços de passagem permaneça reforçando a importância de lugares não especializados para a construção do saber indígena.

\section{Considerações finais}

A partir da identificação e descrição desses lugares, percebe-se que na Aldeia Kondá a educação comunitária tem se caracterizado como um instrumento poderoso para a continuidade e afirmação cultural. Esses processos de

\footnotetext{
9. Antes de ter acesso à água encanada nas residências, as mulheres indígenas lavavam as roupas nas margens do rio. Nesse momento, conversavam sobre a educação dos filhos e relações familiares, constituindo os rios como ponto de encontro coletivo.

10. Entre elas, destaca-se a pesca com a utilização Pari - estrutura trançada com taquara no formato de um cesto comprido, de forma que quando os peixes entram ali, enganados pelas águas turvas do rio, não conseguem mais sair.
} 
aprendizagem necessitam de diferentes arranjos espaciais para que possam se desenvolver, articulando lugares naturais e construídos, de permanência e de passagem, especializados e adaptados.

Nesse contexto, o espaço escolar ganha destaque, tanto por sua função prática fundamental, o ensino, quanto pela edificação de impacto na paisagem, por seus valores simbólicos e principalmente pelas relações humanas que abraça. A escola, projetada sem a participação da comunidade Kaingang, teve reação negativa por parte dos usuários mais por seu processo de projeto do que pela tipologia adotada. A forma concêntrica, ligada à cosmologia de diversos grupos indígenas, se materializa para os Kaingang e os representa, na medida em simboliza relações não hierárquicas no interior da escola, garante maior visibilidade intergrupal e aumenta a interação entre as diferentes classes de alunos e professores. A construção das estruturas anexas à escola (tanto a casa semissubterrânea quanto as áreas cobertas para o artesanato), replica a base formal circular, referenciando os agrupamentos das casas em torno da moradia anciã e a organização das pessoas em torno do fogo de chão.

Vale destacar que, nessa escola, a maioria dos professores é indígena e reside na comunidade, portanto, as fronteiras entre escola e comunidade são porosas e admitem interações de maneira mais contínua e substancial, contribuindo positivamente na formação das crianças. Essa 
proximidade permite trazer a sabedoria tradicional para o espaço escolar, por meio de ações que envolvem os anciãos. Ainda, atividades de contação de histórias em língua Kaingang, preparo de comidas tradicionais e o estímulo aos ensinamentos sobre as ervas medicinais são recorrentes e potencializados na medida em que a própria comunidade constrói espaços específicos para abrigar tais atividades a partir de tecnologia autóctone.

Para além do espaço escolar, as salas de aula a céu aberto, na mata, nas casas dos anciãos, nos percursos e na beira dos rios ampliam as possibilidades do ensinar e do aprender na comunidade. A utilização desses espaços alternativos de transmissão de conhecimento significa a retomada de uma prática tradicional de ensino, uma vez que resgata o papel dos anciãos nos processos de formação das novas gerações e utiliza lugares que transcendem os muros da escola. Ou seja, afirma simbolicamente que a educação indígena, enquanto ensinamento de um modo de viver, extrapola os espaços especializados de ensino e incorpora o território da comunidade como um todo.

Para o povo Kaingang, cuja tradição é alicerçada na oralidade e na relação com elementos da natureza, torna-se mais coerente a construção do saber em espaços livres que contemplem essas questões do que na restrição à internalização espacial da educação proposta pela educação escolar não indígena. Tradicionalmente, os Kaingang 
não necessitavam de delimitações espaciais para o ensino e a organização espacial da comunidade era fonte de inspiração e construção permanente de conhecimento. Por outro lado, a edificação escolar, apesar de não suprir na totalidade as demandas, possibilidades e tradições de construção e transmissão de saberes, pode ser pensada de maneira a permitir e encorajar as práticas culturais de seus usuários, valorizando a transposição de suas fronteiras e incentivando ações que integram pessoas e natureza na construção dos futuros culturais pretendidos pela comunidade.

\section{Referências}

BORBA, T. Actualidade indígena. Coritiba: Typ e Lytog a Vapor impressora Paranaense, 1908.

BOURDIEU, P. What makes a social class? On the theoretical and practical existence of groups. Berkeley Journal 01 Sociology, n. 32, p. 1-49, 1987.

BRASIL. Constituição da República Federativa do Brasil de 1988. Disponível em: <http://www.trtsp.jus.br/legislacao/constituicao-federal-emendas. Acesso em: 24 de fevereiro de 2020.

. Decreto n.o 26, de 4 de fevereiro de 1991. Dispõe sobre a Educação Indígena no Brasil. Diário Oficial da União, Brasília, DF, 5 fev. 1991. 
. Decreto n. ${ }^{\circ} 6.861$, de 27 de maio de 2009. Dispõe sobre a Educação Escolar Indígena, define sua organização em territórios etnoeducacionais, e dá outras providências. Diário Oficial da União, Brasília, DF, 28 maio 2009.

. Lei n. ${ }^{\circ}$ 9.394, de 20 de dezembro de 1996. Estabelece as diretrizes e bases da educação. Diário Oficial da União, Brasília, DF, 23 dez. 1996.

. Educação, Ministério e do Desporto, Secretaria de Educação Fundamental; Referencial Curricular Nacional para a Educação Infantil. Brasília: MEC/SEF, 1998. v.3.

D'ANGELIS, W. R., VEIGA, J. Habitação e Acampamentos Kaingang hoje e no passado. In: Cadernos do CEOM n.18, p. 213-242. 2003.

DILL, F. M. Linguagem Socioespacial: A Dimensão espacial do modo de viver Kaingang. Tese (Doutorado) - Universidade Federal de Santa Catarina. Programa de Pós Graduação em Arquitetura e Urbanismo. Florianópolis, 2019.

FUNAI. Orientação geral para implantação de edificações e equipamentos públicos de uso coletivo em terras e aldeias indígenas. Ministério da Justiça. FUNDAÇÃO NACIONAL DO ÍNDIO. Diretoria de Promoção ao Desenvolvimento Sustentável. Brasília, 2018. 
JUNIOR, A. G. Estudo Etnográfico sobre Alcoolização entre os Índios Kaingang da Terra Indígena Xapecó: das Dimensões Construtivas à Perturbação. Dissertação (Mestrado) - Universidade Federal de Santa Catarina. Programa de Pós Graduação em Antropologia Social, Florianópolis, 2010.

LÉVI-STRAUSS, C. Antropologia estrutural. Editora Cosac Naify, 2015.

LOZANO, J. E. A. Prática e estilos de pesquisa em história oral contemporânea. In: AMADO M. de M.; FERREIRA J. (Org) Usos \& abusos da história oral. 5. ed. Rio de Janeiro: Editora FGV, 2002, p. 15-25.

MANN, P. H. Métodos de investigação sociológica. Rio de Janeiro: Zahar, 1970.

MULTIPLICA. Casas subterrâneas do povo Kaingang. Disponível em:<http://multiplica.org/subterraneas-do-povo-kanghag >. Acesso em: 12 mar. 2016.

REIS, M. J. A problemática arqueológica das estruturas subterrâneas no Planalto Catarinense. Erechim: Sociedade e arqueologia braseileira. 2007

RHEINGANTZ, P. A. et al. Observando a Qualidade do Lugar: procedimentos para o trabalho de campo. Rio de Janeiro: Faculdade de Arquitetura e Urbanismo, UFRJ, 2009.

ROSA, H. A. A Trajetória Histórica da Escola na Co- 
munidade Guarani de Massiambu, Palhoça/Sc - Um Campo De Possibilidades. Dissertação (Mestrado) Universidade Federal de Santa Catarina, Programa de Pós-Graduação em História, Florianópolis, 2009.

SILVA, L. A. da. A história Kaingang através do Ritual do Kiki. Santa Catarina em História. 2011, p.11-23.

TASSINARI, A. M. I. A educação escolar indígena no contexto da antropologia brasileira. Ilha Revista de Antropologia. Florianópolis, v. 10, n. 1, ago. 2008 , p. 217-244. THEODORSON, G. A.; THEODORSON A. G. A modern dictionary of sociology. London: Methuen, 1970. TOMMASINO K.; FERNANDES R. C. Povos indígenas no Brasil. Disponível em: <www.pib.socioambiental.org/ pt/povo/kaingang >. Acesso em: 30 nov. 2015. 